\title{
Agent-based Modeling and Simulation of Sponsor Effecting on Group Activities
}

\author{
Shulin Liang, Wang $\mathrm{Hu}^{*}$ \\ ${ }^{1}$ Management School, Hunan City University, Yiyang 413000, Hunan, China \\ ${ }^{2}$ Hunan New-type Urbanization Institute, Yiyang, Hunan 413000, China
}

Received: January 13, 2021. Revised: July 2, 2021. Accepted: July 26, 2021. Published: July 30, 2021.

\begin{abstract}
The effects of sponsor on communication group-buying are studied through agent-based modeling and simulation approach. At first, using content analysis we determine the categories and attributes of agents, then based on the Deffaunt original model, establish interaction rules of sponsor-members and member-member whose validity is verified by numerical simulation experiments. Finally, to determine sponsor's impacts on the opinion formation in communication group-buying, the range of his eigenvalue should be modulated. Numerical simulations show that the communication group-buying can be influenced by sponsor. The interaction times can promote the formation of communication group-buying, but the influence is limited. Moreover, the sponsor's professional authority plays a guiding role and his execution has a positive promoting effect in the formation of communication group-buying. Based on the conclusions, the enlightenment function from the perspective of consumer and business is explored.
\end{abstract}

Keywords-Group activity, Opinion evolution, Deffaunt model, Numerical simulation

\section{INTRODUCTION}

$\mathrm{S}_{\text {o }}^{\mathrm{o}}$ OCIAL media (virtual brand communities, blogs and so on), whose development and application are one of the top three breakthroughs for management, not only helps consumers to share their opinions of product and service, but also makes consumers with common demands gather in groups, therefore in this way it provides a platform for the emergence and development of communication group-buying $\left[\begin{array}{ll}1, & 2\end{array}\right]$. Communication group-buying means that by employing social media, consumers with common demands gather together and purchase goods or services from suppliers offline to obtain price advantages and reduce risk, the procedure of which is summarized as follows: after negotiating with a supplier about the minimum number, the possible price and others, a consumer (we call him sponsor) posts some relevant information of group-buying (brand, supplier, the number, deadline, participatory approaches, contact information and so on) and then calls on others to share products at lower prices and risks. When seeing it, they will consult the sponsor about the details and discuss with others whether they should participate in it. To deadline, the sponsor counts up the number of participants and

\footnotetext{
${ }^{*}$ Corresponding author .Wang $\mathrm{Hu}$
}

he would like to bargain effectively with the supplier and determine the details if it reaches the lowest limit. Finally, the participators purchase products or service from the supplier offline after reaching a final agreement $[3,4]$. Thus it shows that communication group-buying can enhance consumer utility, moreover, Chinese customers pay more attention to others' attitudes, so it develops rapidly.

The fast development of communication group-buying has drawn extensive attention of scholars at home and abroad, and the research about sponsor gradually has become a focus. Sponsor refer to a customer initiating collective shopping, whose role is to gather consumers with common needs, bargain with supplier offline, and finally strive for lower price for the group members $[5,6]$. Sponsor has following characteristics: the sponsor is also a participant who will order and purchase with other members to ensure lower price and higher quality; the sponsor only benefits from lower prices like other members without additional benefits; the sponsor generally with higher ability to distinguish and bargain is willing to work for collective interests; the sponsor and other members are stakeholders, so no matter what transaction dispute, the sponsor stands on the side of members firmly and safeguards the vital interests of other members[7, 8]. Since sponsor's professional authority (community level, product knowledge, successful grouping times) and the persuasiveness of information(products' superiority and practicability) affect members' uncertainty and risk perception of products emotionally and rationally, he plays an important role in influencing members involved in group-buying, however, at present the main focus of most studies appears to be on the influence of sponsor on individual members, some scholars reveals that the sponsor possesses more experiences of online shopping and professional knowledge compared with subsequent participators, whose execution can affect consumers' intentions to participate in group-buying, what

s more, consumers' trust in the sponsor plays a significant role for their willingness to join in[9]. However, little attention has been devoted to the influence of the sponsor on the formation of group opinions in communication group-buying. Although sponsor does influence individual member, his influence on the formation of collective opinions in communication is uncertain 
but significant, that works for two reasons: on the one hand, during the process of community members exchanging their opinions, individual opinion is affected by not only sponsor but also other members, moreover, individual characteristics also influence their own opinion; on the other hand, as a model of cooperative internet consumption, the formation of communication group-buying demands the joint participation of group members. Therefore, studying the effects of sponsor on the opinion formation in communication group-buying is valuable and meaningful, but it is still blank in the past studies.

The underlying mechanism of sponsor effecting on communication group-buying can be explained by opinion dynamics theory, which explains how unordered individual opinions evolves into group opinions with obvious tendentiousness through interaction rules in system. Opinion dynamics models can be classified into discrete opinion dynamics model and continuous opinion dynamics model [10]. With the development of computer simulation technology, the thought of multi-agent simulation has been gradually applied to the research of opinion evolution, however, at present this kind of studies about opinion evolution is mostly applied in public event or crisis event, but not communication group-buying [11, 12]. Deffaunt model is a continuous opinion dynamics model, and improved Deffaunt model can better reflect opinion evolution in various social situations [13, 14], so, this paper, combining characteristics of communication group-buying and attributes of participators, studies the effects of sponsor on the opinion formation from the perspective of collective in communication group-buying by improving the Deffaunt model. This paper can be divided into three parts: the first step is to determine the categories and attributes of agent. Here, we adopt content analysis to encode relevant literature and interview text materials and frequency analysis to confirm influences factors about individual member changing opinion; the second is to establish interaction rules on the base of the Deffaunt original model, which includes rules of sponsor-members and member-member, by combining improved ways of other literatures and the results of content analysis; the last is to conduct numerical simulation experiments. To determine the effects of sponsor characters on the opinion formation in communication group-buying, we verify the efficiency of interaction rules, adjust the range of sponsor characters and simulate the formation of opinion in different value ranges of sponsor characters.

\section{CONFIRMATION OF CATEGORIES AND ATTRIBUTES OF AGENT}

\section{A. Content Analysis}

The paper collects and sorts out literatures related to the impacting factors of members involved in group-buying, and investigates some Chinese famous communication group-buying websites such as Changsha Zero Association (a website about decoration materials), Sina Parent-child Forum (a website about mom\&baby products) and so on. And on this basis, the paper compiles a list of the impacting factors sets covering primary-categories and some secondary-categories and text materials are obtain through depth interview. In aspect of interviewee, to ensure that interviewees understand the research topic, twenty-five senior members whose active time is longer than one year are selected, including forum managers, group manager, sponsor and common members. In aspect of the interview way, unstructured interview outline is designed based on the established impacting factors sets firstly, the interactive question and answer way is adopted on the spot, and at last details related to the research topics are extended according to interviewees' responses. In aspect of the interview time, an hour or so is spent.

After interview, three trained coders are invited to sort out interview text materials, which are samples of content analysis to be coded and counted. And binary data are adopted to code so as to reduce the probability of ambiguity when different coders understanding the same text materials. Then based on the result of literature and text analysis, secondary-categories are discussed and determined. After that text materials are decoded and extracted according to the keywords and information description of secondary-categories. Finally, the reliability and validity of interview content analysis are examined. The result shows that the consistency degrees of coders reach the acceptable level which is more than 0.8 , so from this aspect it is clear that content analysis has good reliability. Moreover, the content encoding of this study has good theoretical and practical basis, coders accept relevant training as well, and the interview materials are pre-coded rigorously, therefore content analysis also has good validity.

The results of data encoding and frequency analysis are presented in table 1. Result shows that there are three reasons for individual member involved in communication group-buying through interaction: the first is information content. If the information is more detailed and objective, members can understand more about product attributes, service attitude and so on, have a definite standpoint more easily as well. The second is the characteristic of sponsor. If sponsor has higher qualification, richer experience and better quality of the interaction with members, members are more likely to be influenced and change their own opinions. The third is individual member's characteristics. If the individual is more likely to trust in others and has the higher conformity, he is easier to be influenced by others' opinions. Based on the results of content analysis, the paper classifies the agents in the system into two types: sponsor and members, which are given corresponding attributes; moreover, each type of agent in the system will publish information to influence others, so the paper will treat the information characteristics as attribute of all agents. 
Tab. 1. Content analysis of influence factors about individual member changing opinion

\begin{tabular}{cccc}
\hline Primary categories & Secondary categories & occurrence frequency & frequency \\
\hline Information content & detailed & 25 & $33 \%$ \\
& objective & 22 & $29 \%$ \\
\cline { 2 - 4 } Sponsor characteristic & professional authority & 40 & $53 \%$ \\
& execution & 45 & $60 \%$ \\
\cline { 2 - 4 } Individual characteristic & conformity & 22 & $29 \%$ \\
& trust degree & 42 & $56 \%$ \\
\hline
\end{tabular}

\section{B. Member Agent}

Based on the result of above, opinion reliability, conformity and trust degree are regard as the individual factors which can influence other members' opinions, thus the attribute of individual member is defined as $A_{j}\left(B_{j}(t), C_{j}(t), D_{j}, q_{j i}(t)\right)$.

$B_{j}(t)$ represents the member $j$ 's attitude of participating in the group-buying at time $t$, which is in the continuity interval $[0,1]$. If $\mathrm{j}$ completely accepts the group-buying, $\mathrm{B}_{\mathrm{j}}(\mathrm{t})=1$; if he doesn' $\mathrm{t}$ believe it at all, $\mathrm{B}_{\mathrm{j}}(\mathrm{t})=0$.

$\mathrm{C}_{\mathrm{j}}(\mathrm{t})$ stands for the opinion reliability of member $\mathrm{j}$ at time $\mathrm{t}$ , that is the information agent $\mathrm{j}$ provided is objective and detailed or not at time $t$. It is in the continuity interval $[0,1]$, where 0 means that member doesn' $t$ provide any information to support his opinion while 1 means that member provides much persuasive information to support his view.

$D_{j}$ denotes the conformity of member $j$, which is in the interval $[0,1]$ and doesn't change over time. 0 denotes that member insists on his own idea and never considers others' views, while 1 denotes that member is indecisive who is always influenced by others.

As for trust degree, the paper introduces an unsymmetrical trust matrix $Q(t)$, in which $\mathrm{q}_{\mathrm{ji}}(\mathrm{t})$ stands for member $\mathrm{j}$ 's trust in member $i$ at time $t$ and is in the interval $[0,1] .0$ stands for full distrust and 1 represents complete trust. In trust matrix, the sum of each row is 1 and the sum of diagonal is 0 . The trust degree between two sides will change after they exchange ideas every time.

\section{Sponsor Agent}

Based on the result of content analysis, sponsor's professional authority, execution and information published all influence members' opinions, so the attribute of sponsor is defined as $\mathrm{E}_{\mathrm{k}}\left(\mathrm{F}_{\mathrm{k}}, \mathrm{G}_{\mathrm{k}}, \mathrm{H}_{\mathrm{k}}, \mathrm{I}_{\mathrm{k}}\right)$.

Likert five scale is the approval degree of a statement with five responses containing "agree strongly", "agree", "uncertainty", "disagree" and "disagree strongly" and accordingly the value of five responses is taken as[0.8,1],[0.6,0.8],[0.4,0.6],[0.2,0.4],[0,0.2] .

$\mathrm{F}_{\mathrm{k}}$ stands for the opinion of sponsor. As the advocator of communication group-buying, Sponsor has clear viewpoint to support group-buying strongly, so his opinion takes value in $[0.8,1]$.

$\mathrm{G}_{\mathrm{k}}$ denotes the opinion reliability of sponsor. As the organizer of communication group-buying, sponsor can find out relevant information and show it on the internet in the form of picture, video and so on to lead members to participate in the communication group-buying, so his opinion reliability should be high and the value is taken in the interval $[0.8,1]$.

$\mathrm{H}_{\mathrm{k}}$ means the professional authority of sponsor, which is in the interval $[0,1]$. 0 means that sponsor has no professional authority without experience of organizing communication group-buying, and 1 means that sponsor has the highest professional authority with longer time in webs, higher activity level and richer group-buying experience.

$I_{k}$ stands for the execution of sponsor, which is in the interval $[0,1] .0$ indicates that sponsor takes a laissez-faire attitude and does nothing after publishing information, while 1 implies that sponsor can organize group-buying activities better, not only interacting with members actively, but also feeding back information to business timely.

\section{INTERACTION RULES}

\section{A. Deffaunt original model}

Bounded confidence model, proposed by Deffaunt et al. , defines individual opinion as a random number within a continuous interval, in which if the opinion difference between two individuals $\mathrm{i}$ and $\mathrm{j}$ selected randomly is less than a threshold that $\left|\mathrm{x}_{\mathrm{i}}-\mathrm{x}_{\mathrm{j}}\right|<\varepsilon$, they interact, otherwise they don't interact. Opinion interaction rules are as follows:

$$
\begin{aligned}
& X=X+u\left(X^{\prime}-X\right) \\
& X^{\prime}=X+u\left(X-X^{\prime}\right)
\end{aligned}
$$

Parameter $\mu$, playing an important role in Deffaunt model, means the degree of individuals trusting each other and has impact on the speed of opinion formation. Groups with different properties can be found through controlling parameter $\mu$, for example, when $\mu$ equals 0 , both sides of the communication will remain unchanged; when $\mu$ equals $1 / 2$, they will get the average value of their opinions. Both situations above show that individuals with different characteristics, smaller $\mu$ corresponds to obstinate individuals, who don't change their own opinions easily, while larger $\mu$ means that individuals compromise easily. Based on the analysis above and opinion evolution of the real society, the fixation or limitation of parameter $\mu$ isn't reasonable when individual interacting, therefore, many scholars improve parameter $\mu$ in Deffaunt model according to their own researches.

The parameter $\varepsilon$ is also important to group opinion evolution. Suppose $\mu=0.25$, parameter $\varepsilon$ are arbitrarily set as $0.6,0.5,0.3$, $0.2,0.1$ and 0.05 respectively. In Fig1-7, the x-axis represents simulation time step and the y-axis represents the evolutionary process of group opinions. Besides, the running time is set as 1000 and the corresponding simulation results are shown by 
Figure 1, Figure 2, Figure 3, Figure 4, Figure 5 and Figure 6 separately.

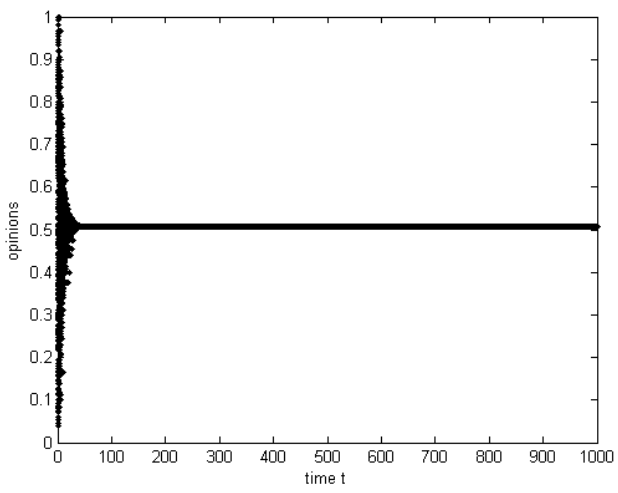

Fig. 1. Plot of opinion evolution in the condition of $\varepsilon=0.6$

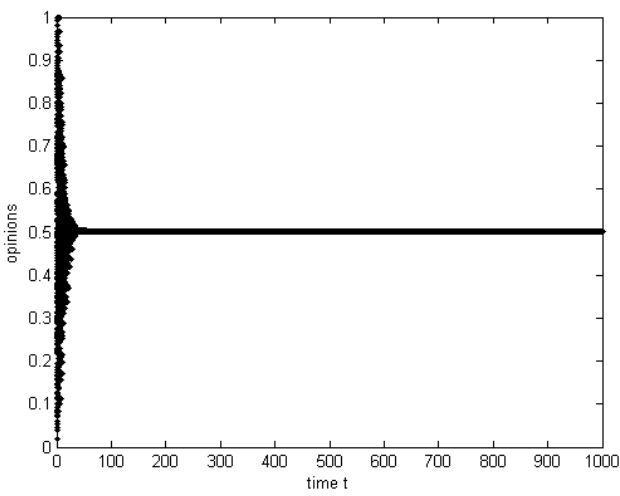

Fig. 2. Plot of opinion evolution in the condition of $\varepsilon=0.5$

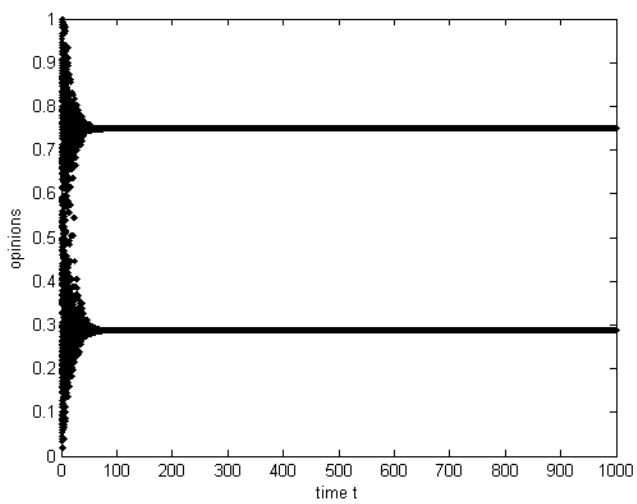

Fig. 3. Plot of opinion evolution in the condition of $\varepsilon=0.3$

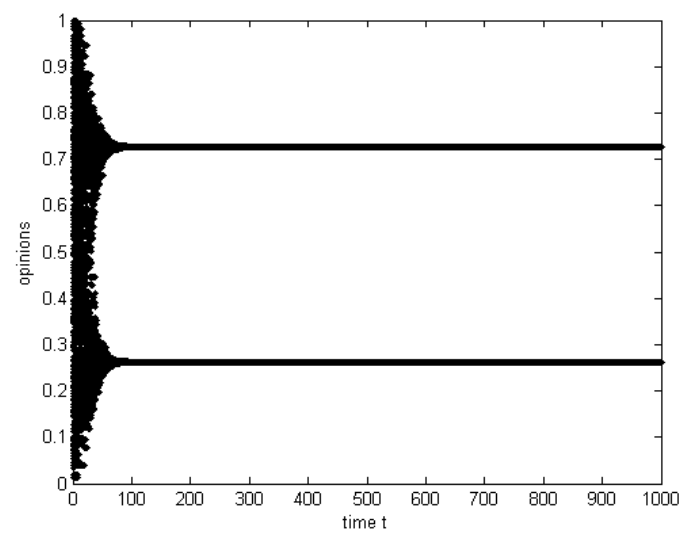

Fig. 4. Plot of opinion evolution in the condition of $\varepsilon=0.2$

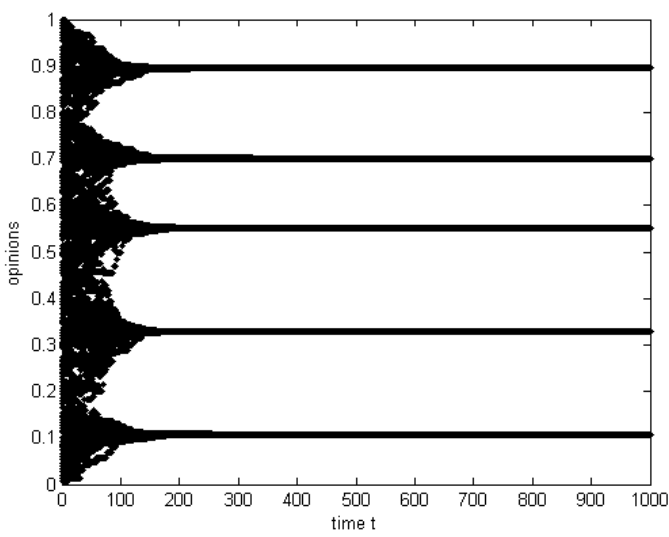

Fig. 5. Plot of opinion evolution in the condition of $\varepsilon=0.1$

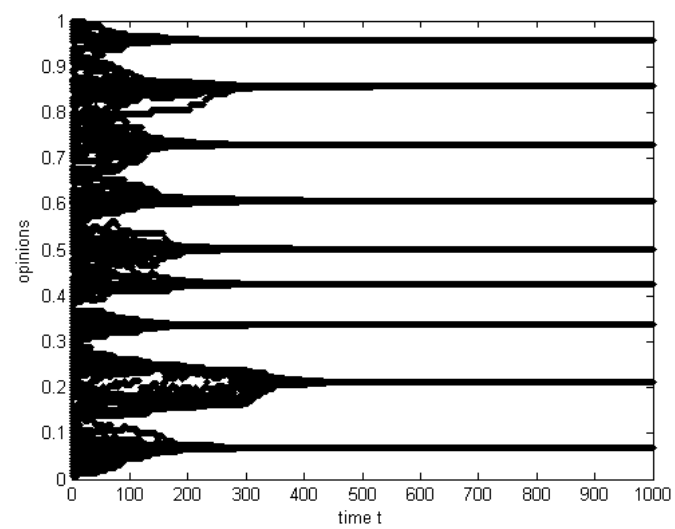

Fig. 6. Plot of opinion evolution in the condition of $\varepsilon=0.05$

We can see from the simulations above that under the condition of $\varepsilon \geq 0.5$, the collective opinions eventually converge, that is, all agents hold the same opinion. As the value of parameter $\varepsilon$ reduces, the collective opinions are divided and form two or more opinion groups, all agents in the same group share a common outlook. Simulation results about Deffaunt model indicate that during the group opinions evolution, cluster $\mathrm{c}$ is in connection with parameter $\varepsilon: \mathrm{c} \approx 1 / 2 \varepsilon$. 


\section{B. The Influence Function}

Based on the Deffuant bounded trust model, some scholars improve parameter $\mu$ as the influence function to construct opinion evolution model of government involvement about crisis information transmission on Internet under Chinese context. According to Deffuant model, parameter $\mu$ is improved as the influence function to structure the simulation model of media leading public opinion in crisis events under Chinese context. In addition, some scholars take other models as foundations to explore the effect of influence factors on propagation tendency about internet crisis information through combining constructed influence function and adjusting parameter value of influence factors in model $[15,16]$. The communication group-buying also happens in Chinese context, therefore, based on above study, improving parameter $\mu$ as influence function is reasonable in this paper.
Through above analysis, we believe that the change of member's opinion is proportional to his conformity, his private opinion unreliability and trust degree in other member respectively, so the influence function of member $i$ to member $j$ is defined as $f(i, j)=a_{1} q_{j i}(t)+a_{2} D_{j}+a_{3}\left(1-C_{j}(t)\right) \quad a_{1}+a_{2}+a_{3}=1$.

The paper adopts analytic hierarchy process (AHP) to determine weight coefficient. Firstly some network marketing experts and the forum manager of Changsha Zero Forum are invited to have informal discussions who are informed of the contents of AHP. After that, they are made to evaluate and sort indexes. And then judgment matrix, which is obtained according to Saaty's 1-9scaling method, is computed using matlab 8.0 and corrected repeatedly based on consistency test. The final result is shown in Table 2, so the influence function is $f(i, j)=0.4 q_{j i}(t)+0.15 D_{j}+0.45\left(1-C_{j}(t)\right)$

Tab. 2. The weight set

\begin{tabular}{cccccc}
\hline & trust & conformity & unreliability & weight & consistency test \\
\hline trust & 1 & $8 / 3$ & $8 / 9$ & 0.4 & \\
conformity & $3 / 8$ & 1 & $1 / 3$ & 0.15 & $\mathrm{CR}=0<0.1$ \\
unreliability & $9 / 8$ & 3 & 1 & 0.45 & \\
\hline
\end{tabular}

The more positive attributes the people who send information has, the stronger the persuasion of the information is. In communication group-buying, as the positive attribute of sponsor, professional authority and execution influences members' opinions positively. And the change of member opinion is proportional to his conformity and opinion unreliability, so the influence function of sponsor $k$ to member $j$ is $g(k, j)=b_{1} H_{k}+b_{2} I_{k}+b_{3} D_{j}+b_{4}\left(1-C_{j}(t)\right) \quad b_{1}+b_{2}+b_{3}+b_{4}=1$

Similarly, the paper adopts analytic hierarchy process (AHP) to determine weight coefficient. The influence function is $\mathrm{g}(\mathrm{k}, \mathrm{j})=0.3 \mathrm{H}_{\mathrm{k}}+0.4 \mathrm{I}_{\mathrm{k}}+0.2 \mathrm{D}_{\mathrm{j}}+0.1\left(1-\mathrm{C}_{\mathrm{j}}(\mathrm{t})\right)$

\section{Rule between sponsor and members (Rule 1)}

As the organizer and executor of communication group-buying, sponsor has important influence on all members, and he is impossible to change his own opinion of supporting group-buying strongly, as a result in the communication between sponsor and members, once a member sees the information published by sponsor, he first compares his opinion reliability with sponsor's--if he exceeds sponsor's in opinion reliability, he will not be affected by sponsor, otherwise, if the opinion reliability of members is low, in other words, the information he knows is not as comprehensive and extensive as sponsor's, he will communicate with sponsor about group-buying and be affected by him. In addition, according to the process of communication group-buying, after sponsor publishes information about group-buying, members interact with sponsor to understand some details and then communicate mutually, therefore, in the numerical simulation experiment, the interaction between sponsor and members is simulated firstly, and then the interaction among numbers is simulated. According to the Deffaunt model and the above analysis, the interaction rule between sponsor and members are as follows:

$$
\text { If } \mathrm{G}_{\mathrm{k}}>\mathrm{C}_{\mathrm{j}} \text { ， }
$$

$$
\begin{aligned}
& B_{j}(t+1)=B_{j}(t)+\left(F_{k}-B_{j}(t)\right) g(k, j) \\
& C_{j}(t+1)=C_{j}(t)+\left(G_{k}-C_{j}(t)\right) g(k, j)
\end{aligned}
$$

\section{Rule among numbers (Rule 2)}

In communication group-buying, members communicate and interact with each other. According to Deffaunt model, interaction rule among members are as follows: at each time step, two members are chosen randomly and non-repeatedly, which will influence each other if the difference value of their opinions is in a given confidence level, that is, when the difference $\left|B_{i}(t)-B_{j}(t)\right|$ is less than a certain confidence level, agent $i$ and agent $j$ are likely to communicate and interact, if agent $i$ 's opinion reliability is greater than agent $j$ 's, agent $j$ is affected by agent $i$, and change his own opinion, opinion reliability and trust matrix. Similarly, if agent $j$ is greater than agent $i$ in opinion reliability, agent $i$ is affected by agent $j$, and change his own opinion, opinion reliability and trust matrix. So the interaction rule is as follows:

$$
\begin{aligned}
& (1) \text { if } \mathrm{C}_{\mathrm{i}}(\mathrm{t})>\mathrm{C}_{\mathrm{j}}(\mathrm{t}) \text { ， and }\left|\mathrm{B}_{\mathrm{i}}(\mathrm{t})-\mathrm{B}_{\mathrm{j}}(\mathrm{t})\right|<\varepsilon, \\
& B_{j}(t+1)=B_{j}(t)+\left(B_{i}(t)-B_{j}(t)\right) f(i, j) \\
& C_{j}(t+1)=C_{j}(t)+\left(C_{i}(t)-C_{j}(t)\right) f(i, j) \\
& q_{j i}(t+1)=q_{j i}(t)\left(1+B_{j}(t) / B_{i}(t)\right) \\
& (2) \text { if } \mathrm{C}_{\mathrm{j}}(\mathrm{t})>\mathrm{C}_{\mathrm{i}}(\mathrm{t}) \text {, and }\left|\mathrm{B}_{\mathrm{j}}(\mathrm{t})-\mathrm{B}_{\mathrm{i}}(\mathrm{t})\right|<\varepsilon, \\
& B_{i}(t+1)=B_{i}(t)+\left(B_{j}(t)-B_{i}(t)\right) f(j, i) \\
& C_{i}(t+1)=C_{i}(t)+\left(C_{j}(t)-C_{i}(t)\right) f(j, i) \\
& q_{i j}(t+1)=q_{i j}(t)\left(1+B_{i}(t) / B_{j}(t)\right)
\end{aligned}
$$


(3)if the difference value of their opinions exceeds a certain confidence level, that is $\left|\mathrm{B}_{\mathrm{j}}(\mathrm{t})-\mathrm{B}_{\mathrm{i}}(\mathrm{t})\right| \geqq \varepsilon$, their opinion, opinion reliability and trust matrix remain unchanged.

In addition, if $\varepsilon$ is too low, group opinions don't converge, while if $\varepsilon$ is too high, it isn't coincident with actual facts, from that the parameter $\varepsilon$ is taken as 0.2 .

\section{NUMERICAL SIMULATIONS}

\section{A. Experimental design}

Experiment idea: The experiment is divided into two stages: the examination of interaction rules and simulation of sponsor effect. The interaction rules in this paper are based on the Deffaunt model and deduced by related literature, what's more, for making more convincing, the paper collects data of a certain communication group-buying in real life, simulates according to interaction rules, and compares simulation result with group-buying result in real life to verify the effectiveness further. Since what the paper researches is sponsor's effect on communication group-buying, the paper by changing his characteristic value compares the group-buying results in different value range to determine the effect of sponsor's characteristics. So according to the analysis of the preceding context, the paper changes the value range of interaction time, professional authority and execution as well to simulate.

Group Size: According to the study of Dunbar, the group can maintain harmony and consistent in a group size within the range of 100 to 150 . In addition, coupled with the suggests of some internet marketing experts and moderators of Changsha Zero Association, it is supposed that there is a social group size of $\mathrm{N}=120$, that is there are 120 members to participate in communication group-buying.

Attribute Distribution: Based on 80-20 rule, in groups, about 20 percent members have a extreme view of communication group-buying, and about 80 percent have relatively moderate view, that is, in communication, there are 12 members supporting it strongly with the opinion value between $[0.8,1]$, whereas 12 members disagreeing it strongly with the opinion value between $[0,0.2]$, and other 96 members' opinion value is in the interval $(0.2,0.8)$. Other attributes are also divided by $80-20$ rule. In addition, many scholars who research public feelings and consensus think that the distributions of individual opinions are uniformed, so do their attributes. So, it is assumed that opinions, opinion reliability and conformity take values in $[0,0.2]$ of 12 members uniformly, so as in $[0.8,1]$ of 12 members and in $[0.2,0.8]$ of 96 members. All attributes are combined freely.

\section{B. The examination of interaction rules}

The paper collects the data of group-buying which is initiated recently about Gree Air Conditioner to exanimate the interaction rules. The reasons of choosing the activity are as follows: on the one hand, this group-buying is initiated on Changsha Zero Association website, because it is a Chinese famous communication group-buying platform and has a set of complete transaction flow, the website itself doesn't influence the final opinions; on the other hand, the product of communication group-buying is mainly concentrated on mother-infant product and decoration materials, so air-conditioning is the representative product. With the help of the forum manager, 146 questionnaires are sent out to members communicating in the group-buying through e-mail, the contents of which include two parts: scoring their own initial opinions, final opinion and attribute characteristics on a scale of 0 to 1 , scoring the characteristics of sponsor on a scale of 0 to 1 . 132 valid ones were retrieved and statistics analysis shows that members' initial opinions, opinion reliability and conformity basically follow uniformly random distribution in $[0,1]$, and the averages of sponsor's professional authority and execution are 0.91 and 0.12 , respectively. According to interaction rules, the paper adopts matlab8.0 to simulate. In Figure 7, the x-axis represents simulation time step and the $y$-axis represents the evolutionary process of group opinions. Besides, the running time is set as 7000 and simulation result is shown in the Figure7.

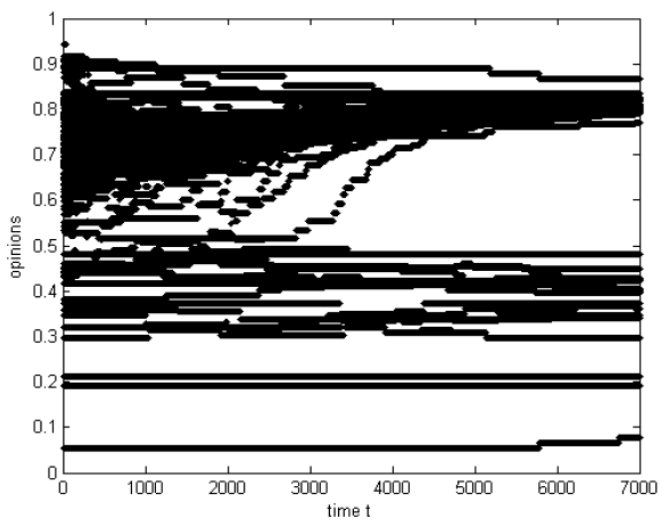

Fig. 7. Plot of group opinions evolution in Gree Air Conditioner communication group-buying

In Figure 7, most of opinions converge to 0.8 or so and a small part of opinions is scattered in $[0.3,0.5]$. The actual situation of the group-buying is that the majority of members assembles and participates in it, while few ones don' $t$ join it and have different opinions. Thus it can be seen that the simulation results are consistent with the reality, moreover, the interaction rules are deducted effectively according to Deffaunt model and related literatures, so the interaction rules are effective.

\section{The interaction times}

According to rules 2, two agents selected randomly and non-repeatedly update their opinions at any given time and simulation result is illustrated in Figure 8. To make a contrastive analysis, sponsor information is added, whose opinion value is in the interval $[0.8,1]$, so is opinion reliability. Besides, attribute characteristics are all in the interval $[0,1]$. Based on rules 1, every member agent interacts with sponsor agent and updates their opinions, and then members interact according to rules 2 and change opinions. Simulation result is 
shown in Figure 9.

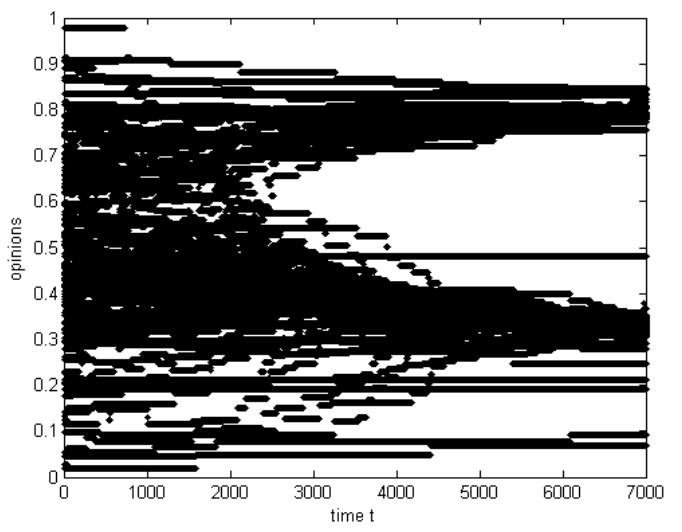

Fig. 8. Plot of opinion evolution in the condition of on sponsor

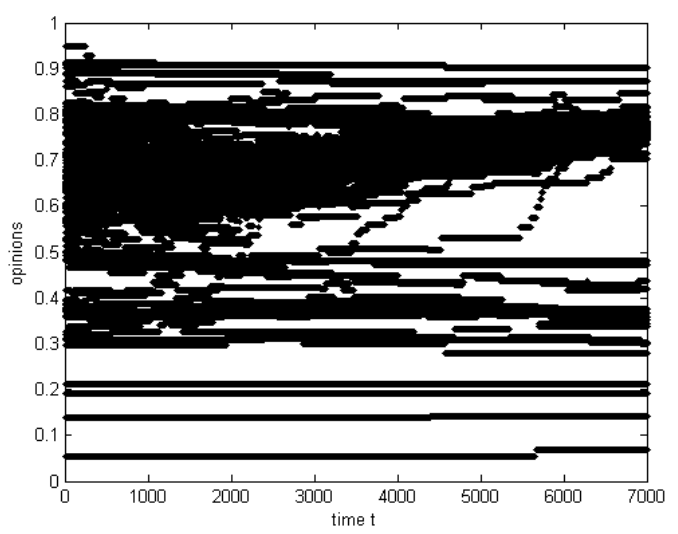

Fig. 9. Plot of opinion evolution in the condition of join sponsor's information

We can see from the simulation above that under the condition of no sponsor, collective opinions are in two different intervals: some members agree, whose opinions converge to the interval $[0.7,0.8]$; others oppose, whose opinions converge to $[0.3,0.4]$. When sponsor information is added, members supporting group-buying increases, whose opinions still converge to the interval $[0.7,0.8]$, while a small part of members are still against it but their opinions are dispersed. The two simulation results show that sponsor can promote the formation of communication and disperse objections.

\section{The interaction times}

Two agents are selected randomly and non-repeatedly through 120 agents, whose opinions update according to rules 2 , and simulation result is illustrated by cyan line of Figure 10, which is the evolutionary process of group average opinion in the state of no sponsor. On the base of the above, after adding sponsor information, every member agent interacts with sponsor agent and updates their opinions according to rules 1 , then members interact according to rules2, in which the interaction times are arbitrarily set as 2, 6, 8, 12, and 24 respectively while the value range of other variables remain the same. Simulation results are shown by yellow line, blue line, red line, green line and black line of Figure 10 separately. In
Figure 10, the $\mathrm{x}$-axis represents simulation time step and the $y$-axis represents the group average opinion, in addition, initial opinion at time 0 refers to members' average opinion after interacting with sponsor.

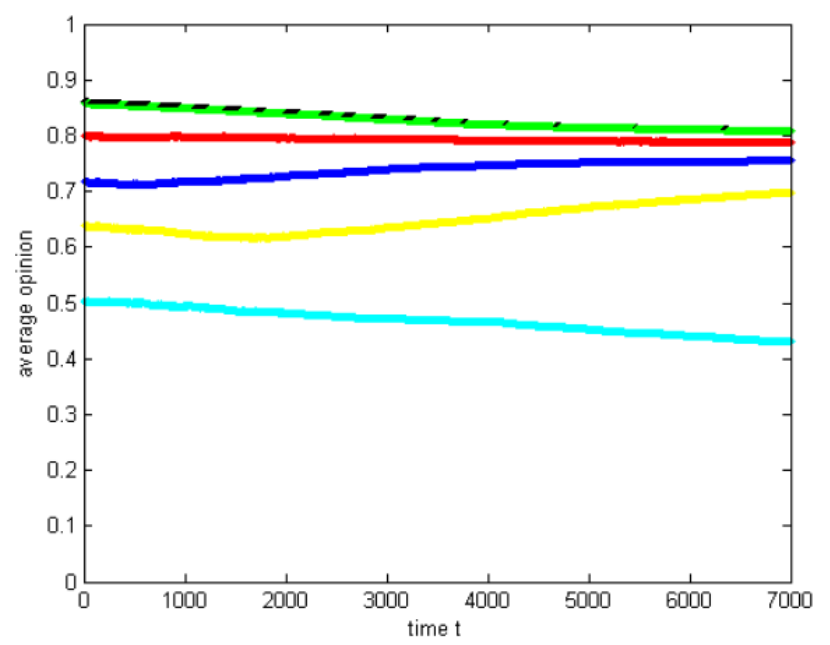

Fig. 10. Plot of the evolutionary process of group average opinion in different interaction times

We can see from the simulation above that group average opinion begins in 0.5 and then declines under the condition of no sponsor, however, when sponsor information is added, initial average opinion raises. And with the interaction times increasing, initial average opinion, as well final average opinion increases gradually, but when the interaction times reach a certain level, group average opinion is tended to be stable. Figure 10 reveals that the interaction times can push the formation of communication, but the effect is limited.

\section{E. Sponsor characteristics}

According to content analysis above and related literatures, sponsor's characteristics have effects on individual members, but the influence on the formation of communication group-buying is unknown, so the parameters of sponsor characteristics are changed to verify it. The paper firstly sets the value of professional authority in the interval $[0,0.2]$, then improves it in the interval $[0.8,1]$. Simulation results are shown by black line and green line of Figure 11 respectively. Similarly, vary the value of execution from $[0,0.2]$ to $[0.8,1]$ and simulation results are shown by black line and green line of Figure 12 respectively. 


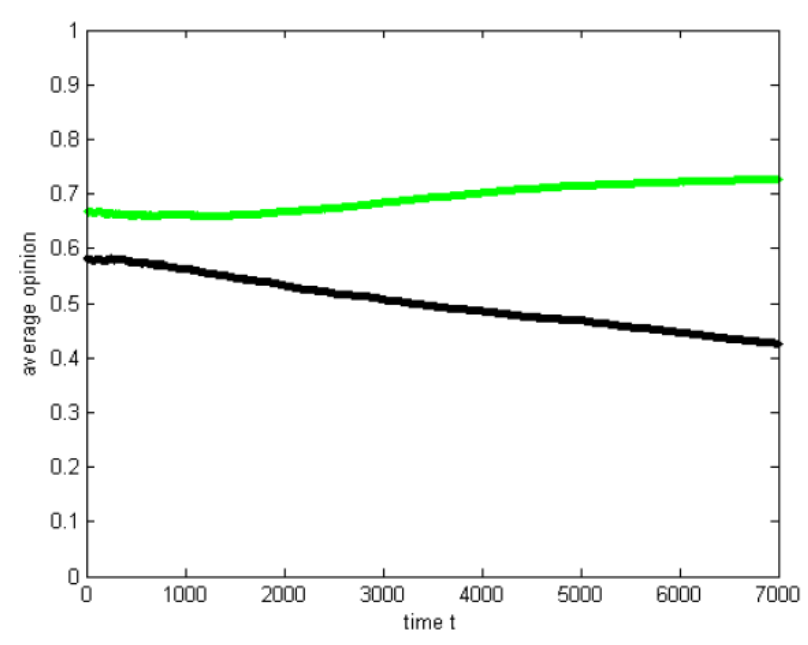

Fig.11. Plot of the evolutionary process of group average opinion in different professional authority

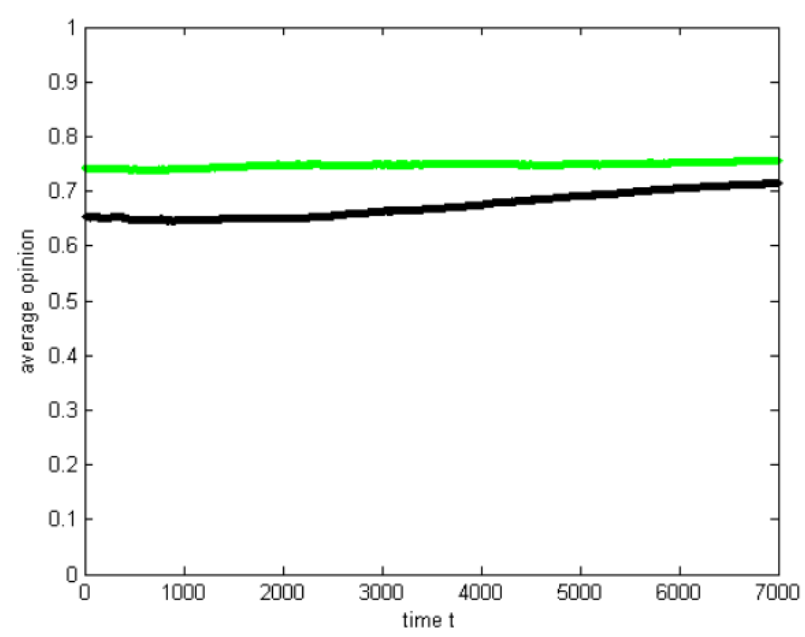

Fig.12. Plot of the evolutionary process of group average opinion in different execution

As shown in Figure 11, when the value of professional authority is in the interval $[0,0.2]$, group average opinion is in decline and the final group average opinion is below 0.5 , but when the value is increased to $[0.8,1]$, initial group average opinion rises and the final group average opinion is above 0.7 , which shows sponsor professional authority plays a guiding role in the formation of communication group-buying. While from Figure 12, when the value of execution is increased to $[0.8,1]$ from $[0,0.2]$, group average opinion at each time rises, which shows sponsor execution has promoting effect in the formation of communication group-buying.

\section{CONCLUSIONS AND APPLICATION}

The paper proposes an opinion evolution model, which is preferable for communication group-buying. The categories and attributes of agent are determined by content analysis firstly. Then influence functions are established and interaction rules are constructed. The last step is to examine the efficiency of interaction rules and adjust the range of sponsor characters to simulate. A series of simulation experiments demonstrate that the formation of group opinions can be influenced by sponsor; the interaction times can promote the formation of communication group-buying, but the influence is limited; sponsor professional authority plays a guiding role and sponsor execution has promoting effect in the formation of it.

Based on the conclusions, the paper explores the enlightenment function from the perspective of consumer and business. From consumer's point of view, if he has a desire to be the sponsor, it is necessary for him to understand the process, learn from experienced members, and investigate business information to ensure members interest before initiating group-buying. After launching it, the sponsor should interact with members actively, feedback information to business timely, and treat all possible disputes fairly. If member wants to participate in group-buying, it's reasonable to examine sponsor information in group-buying websites or from other members. From the aspect of business, if some member wanting to be sponsor gets in touch with business, business should comprehensively understand the member's information and the website where he is. In addition, business also signs protocol with the member to ensure his execution. If business is willing to initiate group-buying in website for product promotion, it is necessary to choose experienced members with good reputation to communicate, and sign protocol with preferred member to ensure the successful development of communication group-buying.

Group factors in communication group-buying make the research complex, furthermore, subject to experiment scene, number of participants and so on, it's difficult to obtain the real data information, therefore, the method of multi-agent simulation is adopted to analyze. The simulation experiments can basically restore opinion evolution of communication group-buying, but there are still differences between the results and facts. With the continuous innovation and breakthrough of computer technology, it has become the fastest way to use social platforms for emotional communication, consultation, appeal, common consumption and so on. Meanwhile, the arrival of big data era also provides the possibility of using real data to study the evolution of group views in the future.

\section{ACKNOWLEDGMENT}

This work was supported in part by the General Project of Hunan Social Science Achievements Review Committee in 2020 (XSP20YBC365)

\section{REFERENCES}

[1] J. M. Mueller, B. Pommeranz, and J. Weisser, et al., "Digital, Social Media, and Mobile Marketing in Industrial Buying: Still in Need of Customer Segmentation? Empirical Evidence from Poland and Germany”, Industrial Marketing Management, vol. 73, no.8, pp. 70-83, 2018.

[2] I. Podgorna, B. Vitalina, H. Natalia, et al., "Modelling and Analysis of Socio-Economic Development of the European Union Countries through the DP2 Method", WSEAS Transactions on Business and Economics, vol.17, pp.454-466, 2020. 
[3] E. Cao, H. Li, "Group Buying and Consumer Referral on a Social Network", Electronic Commerce Research, vol.20, no.1, pp. 21-52, 2020.

[4] T. Ando, "Merchant Selection and Pricing Strategy for a Platform Firm in the Online Group Buying Market", Annals of Operations Research, vol.263, no.1-2, pp. 209-230, 2018.

[5] M. Iris, "The Impact of Socio-Economic Changes in Tourism on the Business Specialization of Travel Agencies", WSEAS Transactions on Business and Economics, vol.17, pp.345-367, 2020.

[6] H. Xu, "Is More Information Better? An Economic Analysis of Group-Buying Platforms", Journal of the Association for Information Systems, vol.19, no.21, pp. 1130-1144, 2018.

[7] Y. X. Xia, S. W. Chae, "Sustainable Development of Online Group-Buying Websites: An Integrated Perspective of ECM and Relationship Marketing”, Sustainability, vol.13, no.4, pp. 2366, 2021.

[8] Q. Zhu, R. Zuo, S. Liu, et al. "Online dynamic group-buying community analysis based on high frequency time series simulation", Electronic Commerce Research, vol.20, no.1, pp. 81-118, 2020.

[9] T. Liu, Y. Zhu, and L. Huang, "TGBA: A two-phase group buying based auction mechanism for recruiting workers in mobile crowd sensing", Computer networks, vol.149, no.11, pp. 56-75, 2019.

[10] Semonsen, Justin, Griffin, et al., "Opinion Dynamics in the Presence of Increasing Agreement Pressure", IEEE Transactions on Cybernetics, vol.49, no.4, pp. 1270-1278, 2019.

[11] L. A. Quang ,N. Jung, E. S. Cho, et al., "Agent-Based Models in Social Physics", Journal- Korean Physical Society, vol.72, no.11, pp. 1272-1280, 2018.

[12] Linh, Thi, Hoai, et al., "Bounded Confidence Gossip Algorithms for Opinion Formation and Data Clustering", IEEE Transactions on Automatic Control, vol.64, no.3, pp. 1150-1155, 2019.

[13] X. M. Si, C. Li, "Bounded Confidence Opinion Dynamics in Virtual Networks and Real Networks", Journal of Computers, vol.29, no.3, pp. 220-228, 2018.

[14] A. Lu, Z. Ding, Y. Liu, et al., "An Evolution Model of Group Opinions Based on Social Judgment Theory (August 2018)", IEEE Access, vol.6, pp. 69288-69293, 2018.

[15] R. Basak, S. K. Ghosh, S. Sural, "Influence Modeling of Opinion Switching by Twitter Users in Public Shaming Events", Social Network Analysis and Mining, vol.10, no.1, pp. 1-11, 2020.

[16] W. Liang, C. Shen, X. Li, et al., "Influence Maximization in Signed Social Networks With Opinion Formation", IEEE Access, vol.7, no.99, pp.68837-68852, 2019 .

\section{Creative Commons Attribution License 4.0 (Attribution 4.0 International, CC BY 4.0)}

This article is published under the terms of the Creative Commons Attribution License 4.0 https://creativecommons.org/licenses/by/4.0/deed.en_US 